\title{
Endoscopic papillotomy and removal of gall stones
}

\author{
M CLASSEN, L SAFRANY
}

British Medical fournal, 1975, 4, 371-374

\begin{abstract}
Summary
Endoscopic papillotomy was attempted in 59 patients with extrahepatic obstruction of the biliary duct system and was actually performed in 50 patients. $A$ special high-frequency diathermy knife was introduced via a duodenoscope into the terminal common bile duct and the roof of the papilla was incised. In 33 out of 39 patients with choledocholithiasis the stones passed into the duodenum spontaneously or were removed endoscopically. Papillary stenosis without ductal stones was successfully treated with this method in eight out of 11 patients. One perforation of the duodenocholedochal junction occurred and was repaired surgically. Endoscopic papillotomy and stone extraction is a relatively safe and effective method of treating extrahepatic jaundice.
\end{abstract}

\section{Introduction}

The ampulla of Vater, situated as it is at the opening of the pancreatic and common bile ducts, plays a crucial part in the function of the upper gastrointestinal tract. Narrowing or complete occlusion of the papillary duct systems produces dramatic clinical syndromes. Fibrocystic or adenomatous forms of papillary stenosis without any inflammation may occur, particularly in older men. ${ }^{1}$ Malignant growths may also restrain adequate drainage. The most important causes of papillary stenosis are diseases of the biliary systems. In only $8 \%$ of patients with an inflammatory stenosis of the papilla of Vater is there no demonstrable disease of the biliary system. Conversely, secondary stenosing papillitis is present in $13 \%$ of patients with cholecystitis with no demonstrable stones, $25 \%$ of patients with gall stones, and $50 \%$ of patients with stones in the bile ducts. ${ }^{2}$

\footnotetext{
I Medical Department, Allgemeines Krankenhaus, Barmbek, Hamburg, Germany

$M$ CLASSEN, $M D$, chief physician and professor
}

Department of surgery, University of Münster, Münster, Germany L SAFRANY, MD, director of endoscopy clinic
We consider that stones in the common bile duct, which always lead to complications, and papillary stenosis, which is associated in about half the cases with choledocholithiasis, are absolute indications for surgery, the aim being to re-establish normal drainage of the bile ducts. The endoscopic approach to the ampulla of Vater and the development of a suitable papillotome made endoscopic papillotomy possible. Animal experiments confirmed that therapeutic endoscopic papillotomy was indeed feasible,$^{3-5}$ and the first endoscopic papillotomy in man was performed in $1973 . .^{6}$

\section{Patients and methods}

Endoscopic diathermic papillotomy was attempted in 59 patients. All had symptoms of cholestasis due to inadequate drainage of the biliary system. In 50 patients endoscopic papillotomy was actually performed. The indications were choledocholithiasis in 39 patients and stenosis of the papilla of Vater in 11. Sixteen patients were men, and 16 were over 70 years of age.

Endoscopes-Olympus JF-B2 and GF-B2 duodenoscopes were used as for endoscopic retrograde cholangiopancreatography.

Papillotome-A high-frequency diathermy knife developed by Demling and Classen ${ }^{2}$ was used (fig 1). It consists of a wire fixed to a plastic catheter which can be passed through the instrument channel of the duodenoscope and acts as a cutting knife. Contrast material can be injected through the catheter to check that the instrument is positioned correctly. The catheter is bent by pulling the wire, thus stretching the wire taut.

Energy source-The Erbotom FR-2 (Erbe, Tübingen) or Olympus PSD diathermy unit was used.

Stone extractor-The Dormia catheter (Storz Co) used to extract the stones consists of a wire basket that, in the closed position, can be inserted into the bile duct and when opened is suitable for extracting stones (fig 2).

\section{TECHNIQUE}

Firstly the anatomy of the pancreatic and common bile ducts was shown by endoscopic retrograde cholangiopancreatography. ${ }^{8} 9$ Special attention was paid to showing a common channel and locating the narrowed segment of the bile duct. When the papillotome was introduced into the common bile duct its position was confirmed by screening and documented by taking an $x$-ray picture (fig 3 ). The wire was then pulled taut, and under continous visual control a current was applied intermittently (step 3-5 of the Erbotom unit or step 2-3 of the cutting current of the PSD unit) and the papilla was 


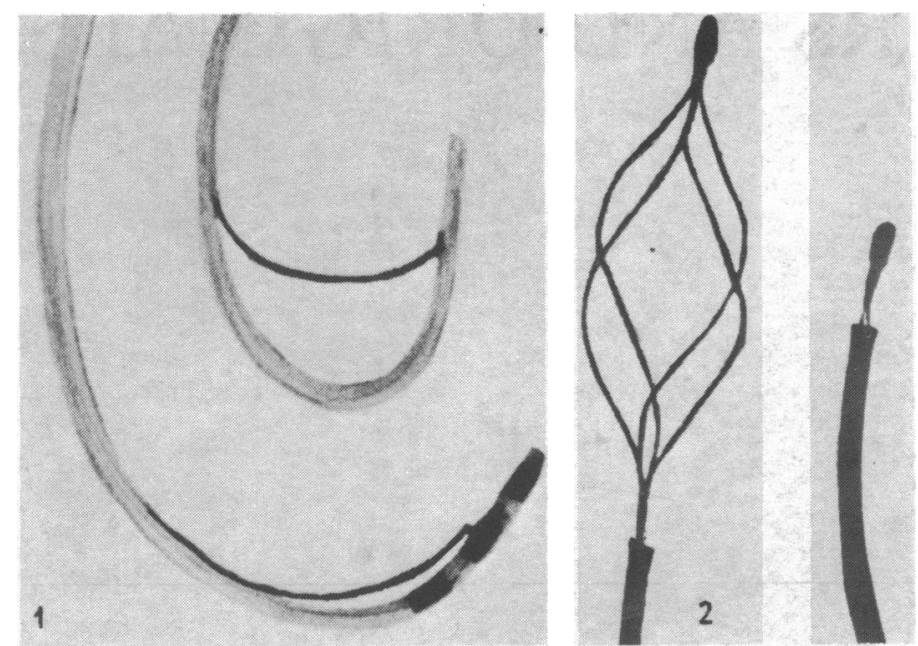

FIG 1-High-frequency diathermy papillotome.

FIG 2-Dormia catheter for gall stone extraction.

performed to exclude the presence of any residual stones, and if some were present these were extracted. To estimate the effect of papillotomy retrograde cholangiography was performed again after 28-35 days. Serum bilirubin, $\gamma$-glutamyl transpeptidase, and amylase estimated in many patients during the early endoscopic follow-up, five to eight days after papillotomy, and also after 28-35 days. The results of laboratory tests were not complete because some patients were admitted by other hospitals or did not attend for a follow-up examination.

\section{Results}

Extrahepatic obstruction was relieved by endoscopic papillotomy in 43 of the 50 patients. The stones of the common bile duct disappeared in 33 out of 39 cases. Endoscopic extraction of the stones was successfully performed in 18 patients, and in 15 patients the stones passed spontaneously after papillotomy. In six patients stones from the common bile duct could be removed only incompletely or not at all. Increasing experience influenced our results: in the last 20 consecutive cases each patient was successfully relieved of cholestasis, and the stones were removed.

Stenosis of the papilla of Vater was relieved by papillotomy in eight of the 11 patients and remained unrelieved in the remaining three: In
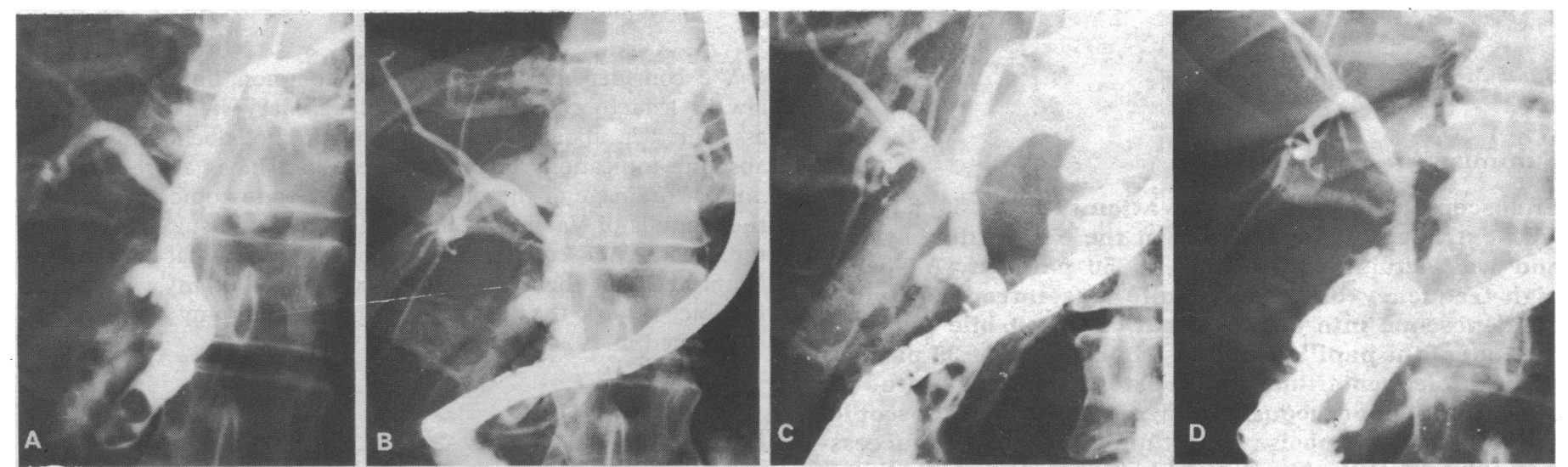

FIG 3-Retrograde cholangiopancreatograms showing (a) two ampullary stones; (b) false position of papillotome: wire is in main pancreatic duct; (c) correct position of papillotome in common bile duct; (d) disappearance of stones and free outflow of contrast medium through broad papillotomy opening one week after papillotomy.

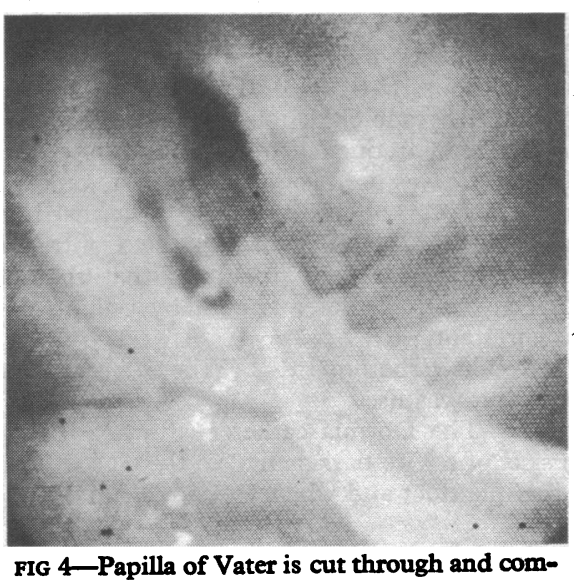
mon bile duct opened. There is no bleeding.

cut open (fig 4). Generally there was little or no bleeding. Immediately afterwards the ducts were cannulated again to show free outflow of contrast material into the duodenum, and $x$-ray films were taken.

Gall stones larger than $1 \mathrm{~cm}$ in diameter, which were unlikely to pass the ampulla of Vater spontaneously, were extracted with the Dormia basket. The Dormia catheter was inserted above the stone, and after pushing the basket through the catheter we attempted to catch and remove the stone under fluoroscopic control (figs 5 and 6). After five to eight days endoscopic retrograde cholangiography was

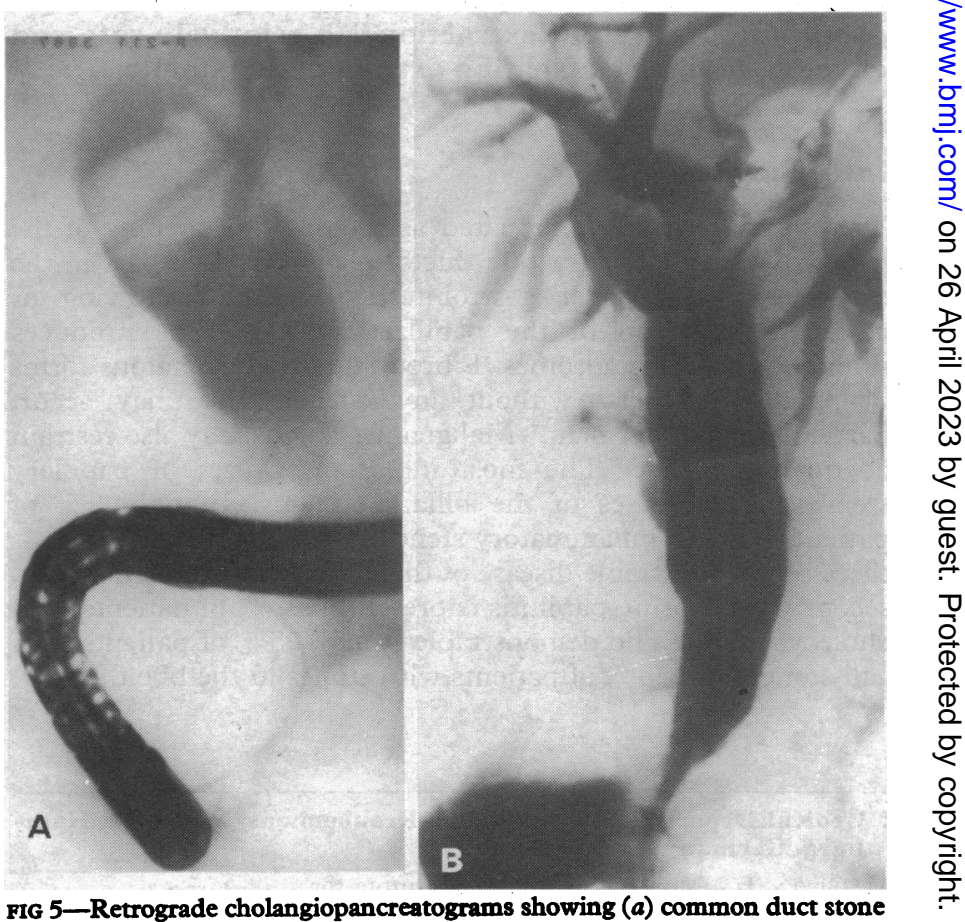

$20 \times 26 \mathrm{~mm}$ (diameter of endoscope is $10 \mathrm{~mm}$ ); (b) disappearance of stone and decrease in diameter of ductus choledochus one week later (stone disappeared spontaneously). 
those who were relieved the success of papillotomy was confirmed by observing the accelerated emptying of contrast material from the ducts (in 10 minutes or less) and the disappearance of the clinical manifestations of cholestasis.

Before papillotomy bilirubin, $\gamma$-glutamyl transpeptidase, and amylase values were raised in most patients. One week after papillotomy values had fallen to normal in most patients, and this trend continued at one month (see table).

Results of blood tests before and after endoscopic papillotomy

\begin{tabular}{|c|c|c|c|}
\hline & $\begin{array}{c}\text { Before } \\
\text { papillotomy }\end{array}$ & $\begin{array}{c}\text { Week } \\
\text { after }\end{array}$ & 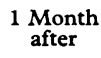 \\
\hline \multicolumn{4}{|c|}{ Bilirubin } \\
\hline $\begin{array}{l}\text { No with normal values } \\
\text { No with raised values } \\
\text { No not tested }\end{array}$ & $\begin{array}{r}6 \\
38 \\
6\end{array}$ & $\begin{array}{r}32 \\
11 \\
7\end{array}$ & $\begin{array}{r}30 \\
4 \\
16\end{array}$ \\
\hline $\begin{array}{l}\text { No with normal values } \\
\text { No with raised values } \\
\text { No not tested }\end{array}$ & $\begin{array}{c}\gamma \text {-Glutamyl tr } \\
2 \\
35 \\
13\end{array}$ & $\begin{array}{r}\text { idase } \\
23 \\
13 \\
14\end{array}$ & $\begin{array}{r}24 \\
3 \\
23\end{array}$ \\
\hline $\begin{array}{l}\text { No with normal values } \\
\text { No with raised values } \\
\text { No not tested }\end{array}$ & $\begin{array}{l}32^{A m y l} \\
3 \\
15\end{array}$ & $\begin{array}{r}28 \\
1 \\
21\end{array}$ & $\begin{array}{l}19 \\
1 \\
30\end{array}$ \\
\hline
\end{tabular}

The patients tolerated papillotomy well. They felt no pain at the time of incision and only four noted a slight feeling of heat during application of diathermy. From the point of view of the patient papillotomy is no greater procedure than endoscopic retrograde cholangiopancreatography alone.

Complications-One patient developed a perforation of the junction where the common bile duct enters the duodenum. After papillotomy air and contrast material could be visualised retroperitoneally. The defect was repaired surgically, and the patient made a good recovery.
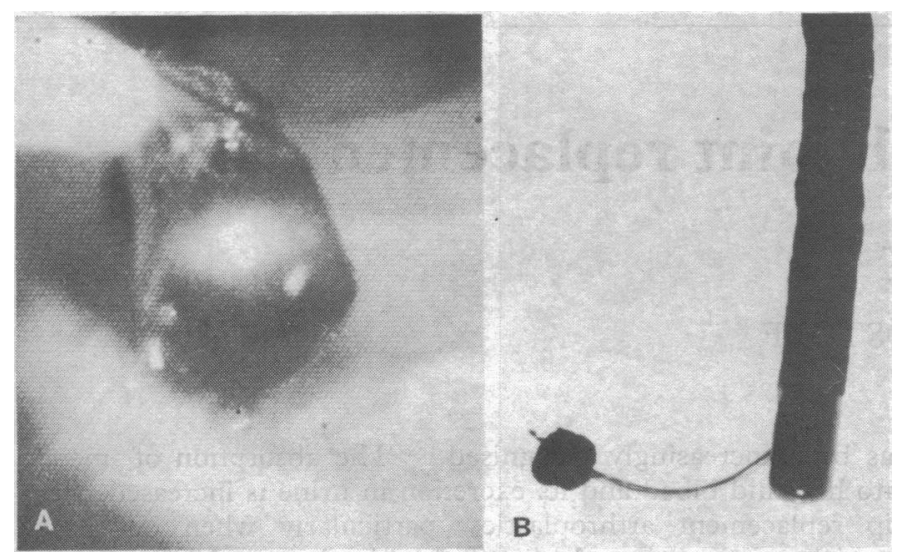

FIG 6-(a) Round black stone is extracted from common bile duct. (b) Endoscope with extracted stone.

\section{Discussion}

Endoscopic papillotomy was always successful when the instrument could be introduced into the common bile duct. This was achieved in 50 of our 59 patients $(85 \%)$. This corresponds to the success rate for diagnostic biliary cannulation. ${ }^{10}$

The applied papillotome has many advantages. Firstly, it is easy to confirm that the tip of the instrument is in the common bile duct by instilling contrast material and screening; damage to the pancreas and pancreatic duct can thus be prevented. Secondly, the direction of the cut can be directed endoscopically by stretching the wire. Thirdly, the length of the incision can be controlled by the bend of the wire and the time during which the current is applied. We incised the roof of the papilla and the major duodenal fold covering the papilla, making a cut 10-15 $\mathrm{mm}$ long. After the incision was made the green or yellow mucosa of the bile duct could be seen through it. Complete sphincterotomy was not intended as the common bile duct has an intraduodenal segment of variable length, and this cannot be estimated endoscopically. The longer the cut the greater the risk of perforating the duodenum.

Indications for endoscopic papillotomy are: $(a)$ stones in the common bile ducts of cholecystectomised patients; $(b)$ stones in the common bile ducts of high-risk patients with or without evidence of gall-bladder stones; and $(c)$ papillary stenosis. We diagnosed papillary stenosis if laboratory results suggested cholestasis and if there was an enlarged common bile duct with a diameter of $15 \mathrm{~mm}$ or more, radiologically visible stenosis of the ampullary segment of the common bile duct, and protracted emptying of the contrast material from the bile duct as observed

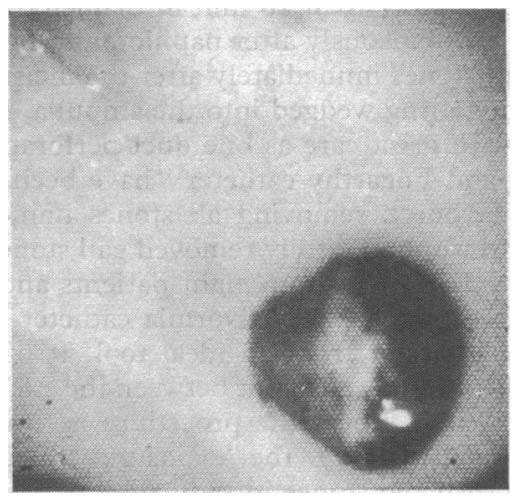

FIG 7-Black stone of about $5 \mathrm{~mm}$ passed spontaneously into duodenum after papillotomy.
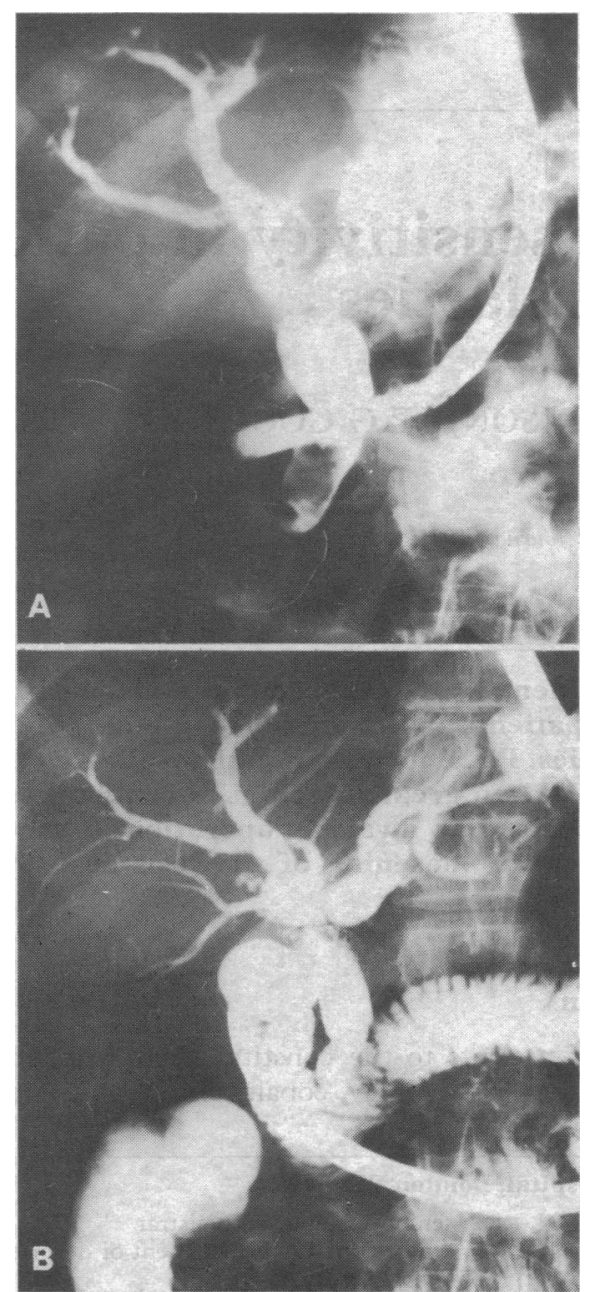

FIG 8 - (a) Ampullary stone $(16 \times 24 \mathrm{~mm})$ causing complete biliary obstruction. (b) One week after papillotomy $2 \mathrm{~cm}$ long stone has disappeared. Diameter of common bile duct decreased from $24 \mathrm{~mm}$ to $15 \mathrm{~mm}$. 
during endoscopic retrograde cholangiography. The first results of intraductal pressure measurements during endoscopic cannulation have been published. ${ }^{12}{ }^{13}$ The return of laboratory values to normal and the disappearance of the complaints after papillotomy verified retrospectively our diagnosis of papillary stenosis.

The contraindications for endoscopic papillotomy are identical to those for the similar surgical procedure-that is, (a) long stenoses of the bile duct; $(b)$ a papilla situated at the edge of a duodenal diverticulum; and $(c)$ when the position of the papillotome in the common bile duct is not completely certain. In the case of very large and impacted stones papillotomy may relieve obstruction but one must warn against enforced extraction.

Ductal stones smaller than $10 \mathrm{~mm}$ in diameter will pass into the duodenum spontaneously after papillotomy (fig 7). We tried to remove larger stones immediately after the incision was made to prevent them getting wedged into the ampulla. Manipulation must be done with great care as bile duct perforations with the Dormia basket and Fogarthy catheter ${ }^{11}$ have been described.

Initially we favoured removing all stones immediately after papillotomy, and we successfully removed gall stones in this way in 11 cases - a single stone from eight patients and two to four stones from three patients. The Dormia catheter used for this purpose, however, is far from an ideal tool. It often does not open completely or it may slide out between the stone and wall of the duct. To try and repeat the procedure is time-consuming and increases considerably the exposure to radiation. An instrument to crush the stones intraductally is needed. In later patients we found that after a papillotomy of adequate length even larger calculi passed spontaneously (fig 8). Recently we have attempted mechanical stone extraction only if a residual stone is still present at the follow-up examination a week after papillotomy.
We failed to remove the stones in 6 patients: in three of these two or three stones were removed and one could not be mobilised. It is remarkable that the jaundice in four patients with retained stones also disappeared after papillotomy. A free bile flow was observed once papillary stenosis was relieved, despite the residual stone. Apart from the inadequacy of the extractor the causes of failure were: a stone tightly adhering to the wall in two cases, a very large stone in two cases, and restenosis of the papillotomy opening in two cases.

A successful papillotomy and extraction of stones results in a complete cure and a failed procedure does not increase the difficulty of open surgery later. In our experience endoscopic papillotomy and stone extraction is relatively safe, and in a high proportion of cases it is effective in treating extrahepatic obstructive jaundice due to gall stones and papillary stenosis.

\section{References}

${ }^{1}$ Dardinsky, V J, fournal of Anatomy, 1934/35, 69, 469.

${ }^{2}$ Hess, W, Surgery of the Biliary Passages and the Pancreas. Princeton, Van Nostrand, 1965.

${ }^{3}$ Kawai, K, et al, Fournal of Kyoto Prefectural University of Medicine, 1973, 82, 353.

${ }^{4}$ Bünte, H, et al, Deutsche medizinische Wochenschrift, 1974, 99, 2312.

${ }^{5}$ Demling, L, et al, Deutsche medizinische Wochenschrift, 1974, 99, 2255.

${ }^{6}$ Classen, M, Medical Tribune, 1973, no 27, p 1.

${ }^{7}$ Classen, M, and Demling, L, Deutsche medizinische Wochenschrift, 1974, 99, 496.

${ }^{8}$ Cotton, P B, et al, Lancet, 1972, 1, 53.

${ }^{9}$ Safrany, L, et al, Gastroenterological Endoscopy, 1973, 19, 163.

10 Safrany, L, Acta Gastro-enterologica Belgica, 1973, 36, 711.

11 Henzel, J H, Blessing, W D, and Deweese, M D, Archives of Surgery, $1971,102,218$

12 Nebel, O T, Gastroenterology, 1974, 66, 818.

13 Vondrasek, P, Eberhardt, G, and Classen, M, Innerere Medizin, 1974 $3,188$.

\title{
Metal sensitivity in patients with joint replacement arthroplasties
}

\author{
M K D BENSON, P G GOODWIN, JONATHAN BROSTOFF
}

British Medical fournal, 1975, 4, 374-375

\section{Summary}

A high incidence of unexpected metal sensitivity was found in patients with metal-to-metal (McKee) hip arthroplasties. Patients with metal-to-plastic (Charnley) prostheses had no greater incidence of metal sensitivity than a control group awaiting operation. If metal sensitivity does occur loosening of the prosthesis may be a complication

\section{Introduction}

Sensitivity of patients to the constituents of implants used in orthopaedic surgery-namely, cobalt, chromium, and nickel-

\section{Middlesex Hospital, London W1N 8AA}

M K D BENSON, FRCS, senior orthopaedic registrar

P G GOODWIN, MRCP, senior registrar, department of dermatology

Department of Immunology, Middlesex Hospital Medical School, London W1P 9PG

JONATHAN BROSTOFF, MRCP, MRCPATH, senior lecturer has been increasingly recognised. ${ }^{1-3}$ The absorption of metal into hair and blood and its excretion in urine is increased after hip replacement arthroplasties, particularly when metal-tometal bearings are used. ${ }^{4}$ Similarly, blood methylmethacrylate levels are raised when acrylic cement is used. ${ }^{5}$ This increased absorption may lead to sensitivity which can be seen as eczematous dermatitis or urticaria. ${ }^{2}$ It has been suggested that metal sensitivity may lead to loosening of metal-on-metal hip prostheses. $^{3}$ The exact incidence and importance of sensitivity after joint replacement remains in doubt and we carried out a study to attempt to resolve these problems.

\section{Patients and methods}

Seventy-two patients who had undergone total hip replacement at the Middlesex Hospital from 1968 to 1972 were examined. A control group was formed by 33 patients awaiting total hip replacement. The patients were well matched for age, the average being 67 years in both groups. The male to female ratio was $1: 2$. Osteoarthritis was the commonest reason for replacement arthroplasty though three of the control group and eight of the test group suffered from rheumatoid arthritis. Thirty-nine patients received a Charnley prosthesis, 32 a McKee, and one a Stanmore. As some replacement arthroplasties were bilateral the 72 patients had a total of 91 protheses. The Charnley prostheses had been implanted for a mean of $4 \cdot 2$ years and the McKee prostheses for a mean of $5 \cdot 2$ years. The Charnley and Stanmore 